\title{
Maquiagem mineral desenvolvida a partir de argilas bentoníticas naturais e tratadas organofilicamente
}

\section{(Mineral make up developed from natural and organophilic bentonite clays)}

\author{
R. K. B.C.Cavalcanti ${ }^{1}$, C. T. Brasileiro ${ }^{1}$, R. O. Macedo ${ }^{2}$,H.S. Ferreira ${ }^{3 *}$ \\ ${ }^{1}$ Universidade Federal da Paraíba, Programa Pós-Graduação em Ciência e Engenharia de Materiais, Brasil \\ ${ }^{2}$ Universidade Federal da Paraíba, Departamento de Ciências Farmacêuticas, Brasil \\ ${ }^{3}$ Universidade Federal da Paraíba, Departamento de Engenharia de Materiais, Cidade Universitária s/n, \\ 58051-900, João Pessoa, PB, Brasil
}

\begin{abstract}
Resumo
A maquiagem mineral é uma formulação cosmética que traz dentre seus componentes matérias-primas minerais a exemplo dos materiais argilosos, sendo as argilas bentonitas mais comumente utilizadas. O uso de argilas bentoníticas do estado da Paraíba no desenvolvimento de formulações de pó mineral para maquiagem foi o objetivo central deste trabalho. Estas argilas foram estudadas também em sua forma organofílica. Inicialmente foi realizada a caracterização físico-química das argilas bentoníticas naturais e organofilizadas, e os resultados indicaram que as argilas apresentam perfil tecnológico com potencial cosmético. Para formulação cosmética foi utilizado $50 \%$ de cada uma das argilas e demais componentes minerais, dando origem a seis diferentes formulações. A partir destas amostras foi estudado seu comportamento estável frente a condições extremas de temperatura. O controle de qualidade toxicológico e microbiológico foi realizado de acordo com os padrões descritos pela Agência Nacional de Vigilância Sanitária (ANVISA) e Farmacopéia Brasileira. As amostras foram testadas para investigação da irritabilidade oftálmica por meio de ensaio in vitro da membrana corioalantóide do ovo da galinha (HET-CAM), e os ensaios microbiológicos foram feitos pelo método de plaqueamento em superfície. Todas as amostras apresentaram-se estáveis quanto às suas características físico-químicas. Nenhuma das formulações apresentou citotoxicidade. O controle microbiológico assegurou a segurança biológica com ausência de bactérias. Palavras-chave: citotoxicidade, maquiagem mineral, argilas bentoníticas.
\end{abstract}

\section{Abstract}

Mineral make up is a cosmetic formulation that brings among its components mineral raw materials such as clayey materials; bentonites clays are most commonly used. The use of bentonite clays from Paraíba state in the development of mineral powder formulations for makeup was the central objective of this work. These clays were also studied in their organophilic form. Initially the physical-chemical characterization of the natural and organophilic bentonite clays was performed, and the results indicated that the clays have a technological profile with cosmetic potential. For the cosmetic formulation 50\% of each of the clays and other mineral components were used, giving rise to six different formulations. From these samples, their stable behavior against extreme temperature conditions was studied. The toxicological and microbiological quality control was performed according to the standards described by ANVISA and Brazilian Pharmacopoeia. Samples were tested for ocular irritability investigation by in vitro chicken egg allosteric membrane (HET-CAM) assay, and the microbiological assays were done by the surface plating method. All samples were stable as to their physicochemical characteristics. None of the formulations showed cytotoxicity. The microbiological control ensured the biological safety with absence of bacteria.

Keywords: cytotoxicity, mineral makeup, bentonite clays.

\section{INTRODUÇÃO}

As argilas são minerais terrosos que apresentam fina granulometria e característica plástica, o que promove maior facilidade em moldá-la quando em contato com água. Possuem em sua constituição química o óxido de alumínio, óxido de silício e alguns óxidos de metais alcalinos e alcalinos terrosos [1]. Na natureza estes materiais são encontrados em abundância e não são materiais de alto custo, isto é, além do baixo custo estes apresentam também fácil acesso. Paralelo

*hebersivini@gmail.com a estes fatores, apresentam características intrínsecas, dentre elas destacamos a elevada CTC (capacidade de troca catiônica), a qual as permitem importante ecletismo em suas aplicações industriais, que incluem desde técnicas simples e portanto tradicionais, a exemplo de sua aplicação na indústria cerâmica como matéria-prima para a produção de louça sanitária, pisos, revestimentos entre outros [2], e alcançam as mais refinadas e delicadas técnicas de produção, em especial ao que se aplica a cosmetologia, a citar seu uso em formulações de maquiagens, shampoos e emulsões para pele [3], e aos fármacos, a exemplo do uso de argilas bentoníticas na entrega de fármacos e ainda na síntese de 
nanocompósitos de argilas-polímeros na engenharia de tecidos [4]. Além de algumas características físico-químicas importantes que as argilas devem apresentar para destinação de sua aplicação em determinado seguimento industrial, em casos particulares a exemplo do seguimento cosmético, existe também a necessidade de que esta apresente certo grau de pureza no que se refere a minerais acessórios e componentes agregados indesejáveis que the são peculiares [5], visto que estes materiais são provenientes da natureza e se formam a partir da iniciativa e manifestações naturais da mesma, é então presumível a presença de outros materiais e minerais acessórios, matéria orgânica e impurezas do meio.

$\mathrm{O}$ uso de materiais argilosos para fins cosméticos, ou mesmo medicinal, trata-se em verdade de uma prática antiga; relatos datam que os egípcios faziam uso de argilas como máscaras faciais [6]. Desde tempos remotos a comunidade indígena faz o uso de argilas no processo de cicatrização de ferimentos, além disso, o uso terapêutico destas argilas tambémé uma prática comum e datada historicamente, a qual foi trazida aos dias de hoje por spas e clínicas estéticas [5]. A bordo de navios houve práticas similares onde os marinheiros faziam uso de argilas para tratamento de desordens internas e externas a exemplo de furúnculos, queimaduras, odores, umidade e outros desconfortos [7]. As argilas de uso mais representativo em seguimento cosmético são as bentonitas, a paligosquita, a caulinita e talco [8]. Estas argilas têm uso tópico ou por ingestão, e são intensamente solicitadas por suas características remineralizante, hidratante e adsorvente [9]. Dentre as argilas acima descritas cita-se a bentonita como objeto especial do presente estudo.

As bentonitas são compostas essencialmente por montmorilonitas. Estas argilas despertam grande interesse industrial e podem ser encontradas em locais em que há, ou tenha havido, a presença de silício, alumínio ou ferro, magnésio e cálcio, em especial, sob forma de cinzas vulcânicas, depositadas em condições em que exista alta umidade e restrita drenagem das águas de intemperismo [1]. As argilas bentoníticas podem ser classificadas em dois grupos a partir de sua capacidade de inchamento, as que incham sensivelmente quando em presença de água e as que não incham [10], mas também podem receber classificação por cátions de compensação presente nestas argilas subdividindo-as em poli ou monocatiônica [11]. As bentonitas brasileiras são em geral policatiônicas com maior presença de cálcio [12]. A nível nacional, em especial no que se refere à região nordeste do país, há facilidade de acesso a jazimentos destes argilominerais; estes por sua vez apresentam interessante perfil tecnológico e propriedades convenientes à indústria [13]. Sob a perspectiva científica são inúmeros os artigos e experimentos que comprovam a eficácia destas argilas na indústria de petróleo [14], porém, quanto à investigação das propriedades e de seu potencial tecnológico para seu uso, aplicação e possíveis benefícios no segmento da indústria cosmética, ainda há muito a ser pesquisado para então gerar decorrente análise. Neste sentido, a caracterização destas argilas bentoníticas, bem como, procedimentos de análise toxicológica e segurança biológica são caminhos obrigatórios a serem percorridos, os quais certamente podem abrir um imenso leque de aplicações para estas, além disso, sua modificação química pode agregar-lhe um potencial tecnológico apreciável. Para tanto a incitação cientifica para estudos a fim de descobrir suas peculiares características e possíveis aplicações fazemse necessária para que seu aproveitamento seja mais eficaz e sensivelmente adequado para suas respectivas finalidades. Delineia-se desta maneira o objetivo central do presente estudo, onde partindo de argilas bentoníticas buscou-se desenvolver formulações cosméticas de maquiagem para aplicação facial segura.

\section{MATERIAIS E MÉTODOS}

As amostras bentonitas utilizadas foram três, sendo duas industrializadas e uma natural, nomeadas da seguinte maneira; argila RF extraída in natura de jazidas da cidade de Sossego-PB; argila DASL também extraída in natura do município de Pedra Lavrada-PB; argila Verde Lodo cedida pela Bentonit União Nordeste (BUN), proveniente da mina Juá II localizada no município de Boa Vista-PB. As demais substâncias que compuseram a formulação cosmética foram todos adquiridos junto à empresa Dipa Química: dióxido de titânio (anatásio), óxido de zinco e óxido de ferro nas cores vermelho e amarelo. O aditivo químico utilizado na pesquisa foi o sal orgânico quaternário de amônio Praepagem $\mathrm{WB}^{\circledR}$ (cloreto de diestearildimetil amônio) produzido pela empresa Clariant. Todas as amostras de argilas foram purificadas por hidrociclone e secas por processo de atomização; posteriormente parte deste material recebeu tratamento. As argilas foram tratadas com sais quaternários de amônio para organofilização por meio da adição de 71,6 $\mathrm{g}$ de argila em água destilada previamente aquecida a \pm 80 ${ }^{\circ} \mathrm{C}$ e submetida à agitação por $20 \mathrm{~min}$, seguida da adição de 30,83 g do surfactante permanecendo por mais $20 \mathrm{~min}$ sob agitação mecânica. A suspensão água + argila + surfactante foi filtrada a vácuo e a massa sólida retida sobre o papel filtro foi levada a estufa para secagem a $\sim 65^{\circ} \mathrm{C}$ por $24 \mathrm{~h}$.

As argilas naturais e organofilizadas foram caracterizadas por meio da investigação de sua composição mineralógica por difração de raios X (DRX), determinação de sua composição química por fluorescência de raios X, averiguação de seu comportamento térmico por análises térmicas (TG - termogravimetria, e DTA - análise térmica diferencial), teor de umidade por meio de secagem em estufa a $110 \pm 1{ }^{\circ} \mathrm{C}$ por $24 \mathrm{~h}$, adsorção de óleo a partir do proposto em "Standard methods of testing sorbent performance of adsorbents" (ASTM F 726-99), e ensaios de densidade aerada e compactada, onde a densidade aerada foi obtida por meio de medição manual da massa de partículas previamente pesada em balança analítica e levada a uma proveta de 250 $\mathrm{mL}$, e sua densidade compactada foi definida também a partir de uma determinada quantidade de massa conhecida por compactação das partículas, para a qual utilizou-se um dispositivo de madeira que determinava a altura das batidas da proveta, sendo este número de batidas adotadas de 30,50, 
Tabela I - Composição das formulações cosméticas à base de bentonita.

[Table I - Bentonite based cosmetic formulations.]

\begin{tabular}{cccc}
\hline Formulação & RF & DASL & VL \\
\hline Argila & $50 \%$ & $50 \%$ & $50 \%$ \\
Dióxido de titânio & $23 \%$ & $23 \%$ & $25 \%$ \\
Óxido de zinco & $12 \%$ & $12 \%$ & $12 \%$ \\
Óxido de ferro (amarelo) & $7 \%$ & $4 \%$ & $8 \%$ \\
Óxido de ferro (vermelho) & $8 \%$ & $11 \%$ & $5 \%$ \\
\hline
\end{tabular}

$100,150,200,250,300,350,400,450$ e 500 , ressaltando-se que toda esta repetição foi necessária para que se garantisse a constância dos resultados. Ensaios de capacidade de troca catiônica pelo método de adsorção azul de metileno e análise granulométrica por via úmida foram realizados apenas para as amostras de argilas sem tratamento. Cada variação argilosa, natural e tratada organofilicamente, deu origem a uma formulação cosmética. Para cada formulação cosmética de maquiagem tem-se o valor de $50 \%$ da composição em massa de argila, de forma a ser o componente predominante, e 50\%, também em massa, dos demais componentes, conforme Tabela I; o dióxido de titânio age com bloqueador solar, o óxido de zinco como antibactericida e antifúngico, e os óxidos de ferro agem com modificadores de coloração. Cada formulação foi desenvolvida em triplicata a partir das quais foram realizados ensaios para controle de qualidade, garantia de segurança microbiológica e toxicológica de todas as formulações teste.

O controle de qualidade foi assegurado por um conjunto de ensaios capazes de aferir esta propriedade. Inicialmente foram realizados ensaios organolépticos desenvolvidos a partir dos critérios descritos pela ANVISA, a qual trata-se do órgão nacional que regulamenta e orienta quanto aos padrões de qualidade e segurança aceitáveis para comercialização, entre outros, dos produtos desenvolvidos na presente pesquisa [15]. Posteriormente foram verificadas as propriedades de fluxo, as quais referem-se ao comportamento reológico do material e englobam os valores de índice de Hausner, valor este que é calculado a partir da razão entre densidade compactada e aerada, bem como os valores de ângulo de repouso medido a partir do deslizamento de partículas a partir de um funil com abertura de $6 \mathrm{~cm}$ e posicionado a uma altura de $9 \mathrm{~cm}$ para uma superfície lisa e plana [16]. $\mathrm{O}$ ensaio de estabilidade acelerada, também inserido no contexto do controle de qualidade das formulações, tentou prever o comportamento destas, bem como possíveis reações entre seus componentes empregando condições extremas de temperatura durante ciclos pré-determinados, sendo os valores adotados para os ciclos de $24 \mathrm{~h}$ a $50 \pm 2{ }^{\circ} \mathrm{C}$ e $24 \mathrm{~h}$ a $-5 \pm 2{ }^{\circ} \mathrm{C}$, durante o período de 15 dias, em acordo com a norma; posteriormente foram avaliadas possíveis alterações físicas e organolépticas. A metodologia utilizada atendeu aos padrões descritos pela ANVISA [15].

Para efeito de controle microbiológico na intenção de averiguar a segurança das formulações desenvolvidas foi empregado o ensaio microbiológico por plaqueamento seguindo as normas descritas na Farmacopéia Brasileira

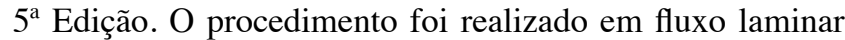
devidamente desinfetado. A preparação das amostras envolveu duas etapas: a homogeneização do conteúdo de cada lote, seguida de diluições seriadas (10-1 e 10-2). A primeira diluição foi obtida através da transferência asséptica de $10 \mathrm{~g}$ de cada amostra para $90 \mathrm{~mL}$ de solução salina $0,9 \%$; posteriormente, $1 \mathrm{~mL}$ desta diluição foi transferida para $9 \mathrm{~mL}$ de solução salina $0,9 \%$, para obtenção da segunda diluição. A análise microbiológica foi realizada em duplicata. A contagem padrão em placas foi realizada através da técnica de semeadura em superfície; para tanto foi inoculado $0,1 \mathrm{~mL}$ de cada diluição em placas de Petri estéreis contendo $21 \mathrm{~mL}$ de Ágar Nutriente, previamente resfriado. Cada alíquota foi espalhada com auxílio de uma alça de Drigalsky. As placas foram invertidas e incubadas a $35 \pm 1{ }^{\circ} \mathrm{C}$ por período de cinco dias. Ao término da incubação as placas foram submetidas a contagem.

A segurança toxicológica das formulações de maquiagem mineral foi avaliada por ensaio de citotoxicidade pelo método da membrana corioalantóide do ovo embrionário da galinha HET-CAM. Foram coletados ovos de galinhas fertilizados em primeiro dia de incubação cedidos pela empresa Guaraves (Sertãozinho-PB). Estes ovos passaram a ser incubados em câmara de aquecimento controlado a $38 \pm 1$ ${ }^{\circ} \mathrm{C}$ e umidade relativa de aproximadamente $70 \%$, durante dez dias. Ao décimo dia de incubação os ovos foram retirados do incubatório e levados à análise HET-CAM. Inicialmente efetuou-se a preparação das amostras, onde estas foram diluídas em três diferentes concentrações nas seguintes proporções (argila/água destilada): $1 \mathrm{mg} / 1 \mathrm{~mL}, 1 \mathrm{mg} / 2 \mathrm{~mL}$ e $1 \mathrm{mg} / 3 \mathrm{~mL}$; para realização do ensaio foi utilizado um ovo para cada diluição. Foi então removida a casca do ovo ao redor da câmara de ar, evidenciando assim a membrana da casca; esta membrana por sua vez também foi retirada cuidadosamente expondo assim a membrana corioalantóide, onde foram aplicados $300 \mu \mathrm{L}$ do produto diluído. Após $5 \mathrm{~min}$ de exposição a membrana corioalantóide foi examinada a fim de observar os efeitos irritantes, a exemplo de hiperemia (congestão sanguínea), hemorragia (escoamento sanguíneos fora dos vasos) e coagulação (formação de coágulo) que porventura ocorressem advindos do produto.

\section{RESULTADOS E DISCUSSÃO}

\section{Argilas bentoníticas naturais e organofílicas}

Na Fig. 1a encontram-se representados os difratogramas das argilas naturais RF, DASL e Verde Lodo. Pode-se observar que os difratogramas são característicos de argilas pertencentes ao grupo das esmectitas. O pico característico da montmorilonita está representado por uma distância interplanar de $17,65 \AA\left(5,00^{\circ}\right)$ para $\mathrm{RF}, 14,71 \AA\left(6,00^{\circ}\right)$ para DASL e $16,05 \AA\left(5,50^{\circ}\right)$ para Verde Lodo. Ainda é possível verificar nos resultados dos ensaios de DRX da 
Fig. 1 presença, embora discreta, de caulinita e quartzo, componentes comuns a todas as amostras bentoníticas; ambos são considerados impurezas características de argilas bentoníticas [17]. Os difratogramas das amostras organofílicas estão representadas na Fig. 1b. As imagens indicam variações nas distâncias interplanares $d_{001}$ e seus ângulos. O aumento da distância interplanar, sendo 31,52 $\AA\left(2,80^{\circ}\right)$ para RF, $30,43 \AA\left(2,90^{\circ}\right)$ para DASL e $32,69 \AA$ $\left(2,70^{\circ}\right)$ para Verde Lodo, e consequente deslocamento do pico (001) para ângulos mais baixos evidencia a presença do tensor entre as camadas do argilomineral [17]. A presença do segundo pico pode evidenciar que parte dos espaçamentos interplanares não foram intercalados pelo cátion do tensoativo; também pode ser indicativo de que existem algumas camadas com maior facilidade de serem intercaladas que outras. O terceiro pico é uma provável indicação de uma argila não hidratada e não organofilizada [17]; para tanto, observa-se que este pico é mais pronunciado na amostra RF que nas demais amostras organofilizadas.

A Tabela II apresenta a composição química das três amostras das argilas bentoníticas; analisando-a é possível observar que as três amostras apresentaram quantidades significativas e próximas, comparando-as umas às outras, de $\mathrm{SiO}_{2}$, o qual se deve à presença dos argilominerais e à sílica livre; esta por sua vez foi proveniente do quartzo, que mesmo presente em quantidades discretas (Fig. 1b) contribui com o percentual do óxido em questão. $\mathrm{O} \mathrm{Al}_{2} \mathrm{O}_{3}$ está provavelmente, em maior parte, combinado na formação dos argilominerais, em geral a caulinita e esmectita [1], fase presente nas amostras de acordo com as análises de difratometria já reportadas. Para as três amostras estudadas os valores deste óxido foram semelhantes, indicando assim presença da fração argilosa em valores próximos para as três amostras. Os teores de $\mathrm{TiO}_{2}$ e $\mathrm{Fe}_{2} \mathrm{O}_{3}$ são valores típicos de argilas bentoníticas do nordeste brasileiro. A presença dos óxidos de $\mathrm{Mg}$ e Ca confirmou a natureza policatiônica das amostras em questão. Os teores para os demais óxidos e o valor de perda ao fogo (PF) estão dentro do esperado para argilas bentoníticas [1], como também para aquelas específicas da região da Paraíba [18].

As Figs. 2 e 3 representam o comportamento térmico das argilas naturais e organofílicas. As Figs. 2a e $2 b$ apresentam comportamento semelhantes entre si, onde em torno de $99{ }^{\circ} \mathrm{C}$ há um intenso pico endotérmico que corresponde à perda de água livre. $\mathrm{O}$ pico endotérmico existente em torno de $470{ }^{\circ} \mathrm{C}$ para estas amostras correspondente à perda de hidroxilas da esmectita e caulinita. O pico endotérmico, a $900{ }^{\circ} \mathrm{C}$, seguido de pico exotérmico, em torno de $935{ }^{\circ} \mathrm{C}$, indica a quebra do retículo cristalino e consequente formação de quartzo $\beta$ resultado do excesso de sílica existente da nucleação da mulita. As curvas de TG indicaram que na amostra RF (Fig. 2a) houve uma perda de massa de 20,29\%, e a a)

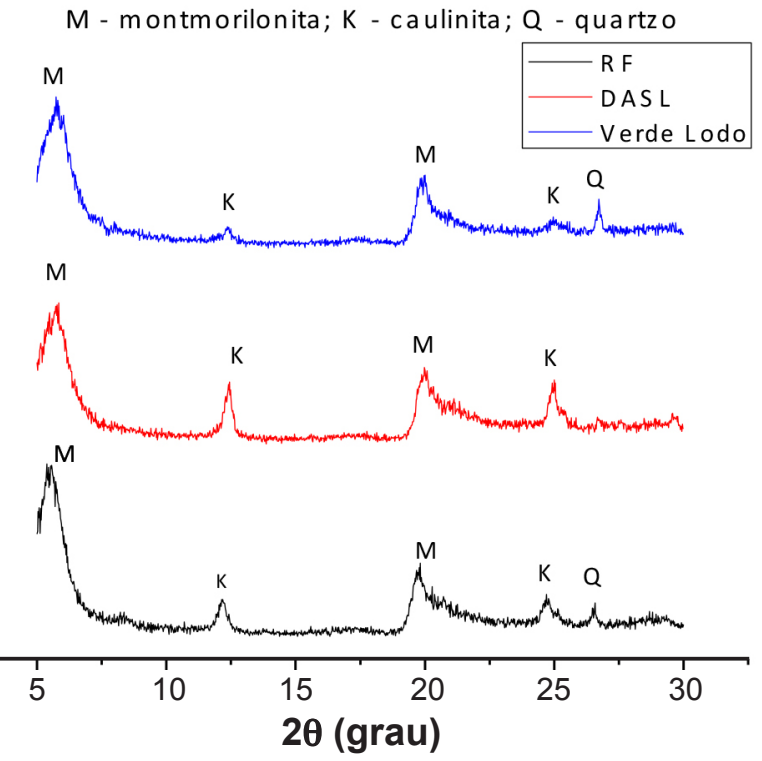

b)

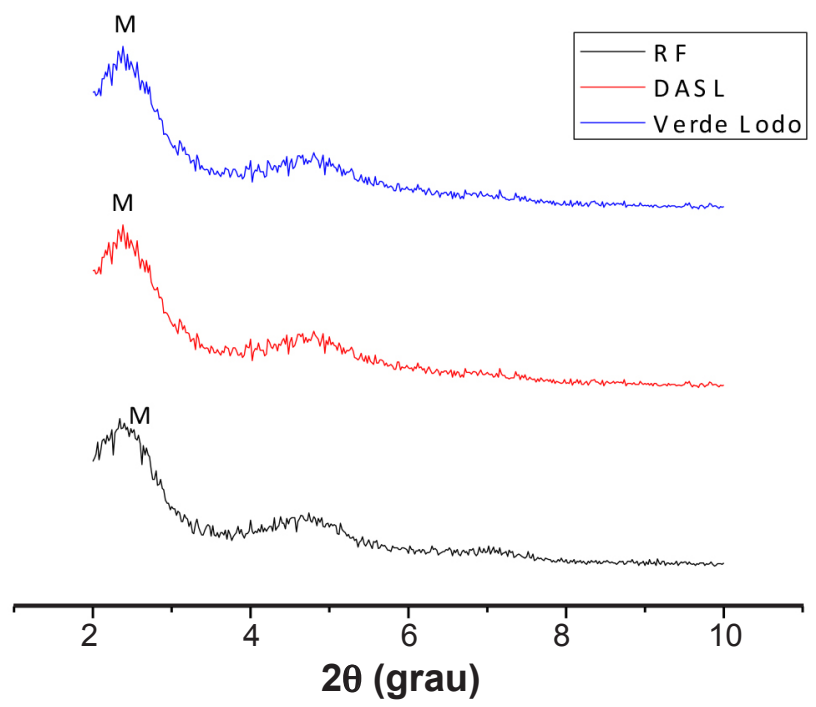

Figura 1: Difratogramas de raios X das argilas RF, DASL e Verde Lodo em estado natural (a) e organofílico (b).

[Figure 1: X-ray diffraction patterns of the RF, DASL and Verde Lodo natural clays (a), and organophilic clays (b).]

Tabela II - Composição química (\% em massa) das argilas bentoníticas naturais.

[Table II - Chemical composition (wt\%) of natural bentonite clays.]

\begin{tabular}{ccccccccccc}
\hline Amostra & $\mathrm{SiO}_{2}$ & $\mathrm{Al}_{2} \mathrm{O}_{3}$ & $\mathrm{Fe}_{2} \mathrm{O}_{3}$ & $\mathrm{MgO}$ & $\mathrm{Na}_{2} \mathrm{O}$ & $\mathrm{TiO}_{2}$ & $\mathrm{CaO}$ & $\mathrm{K}_{2} \mathrm{O}$ & $\mathrm{PF}$ & Outros óxidos \\
\hline $\mathrm{RF}$ & 70,76 & 6,84 & 8,03 & 3,31 & 0,32 & 1,01 & 2,09 & 0,23 & 7,03 & 0,39 \\
DASL & 69,27 & 7,65 & 8,34 & 2,85 & 0,37 & 1,22 & 2,21 & - & 7,67 & 0,35 \\
Verde Lodo & 68,22 & 6,44 & 11,2 & 3,35 & 0,45 & 1,46 & 1,54 & 0,95 & 6,19 & 0,72 \\
\hline
\end{tabular}



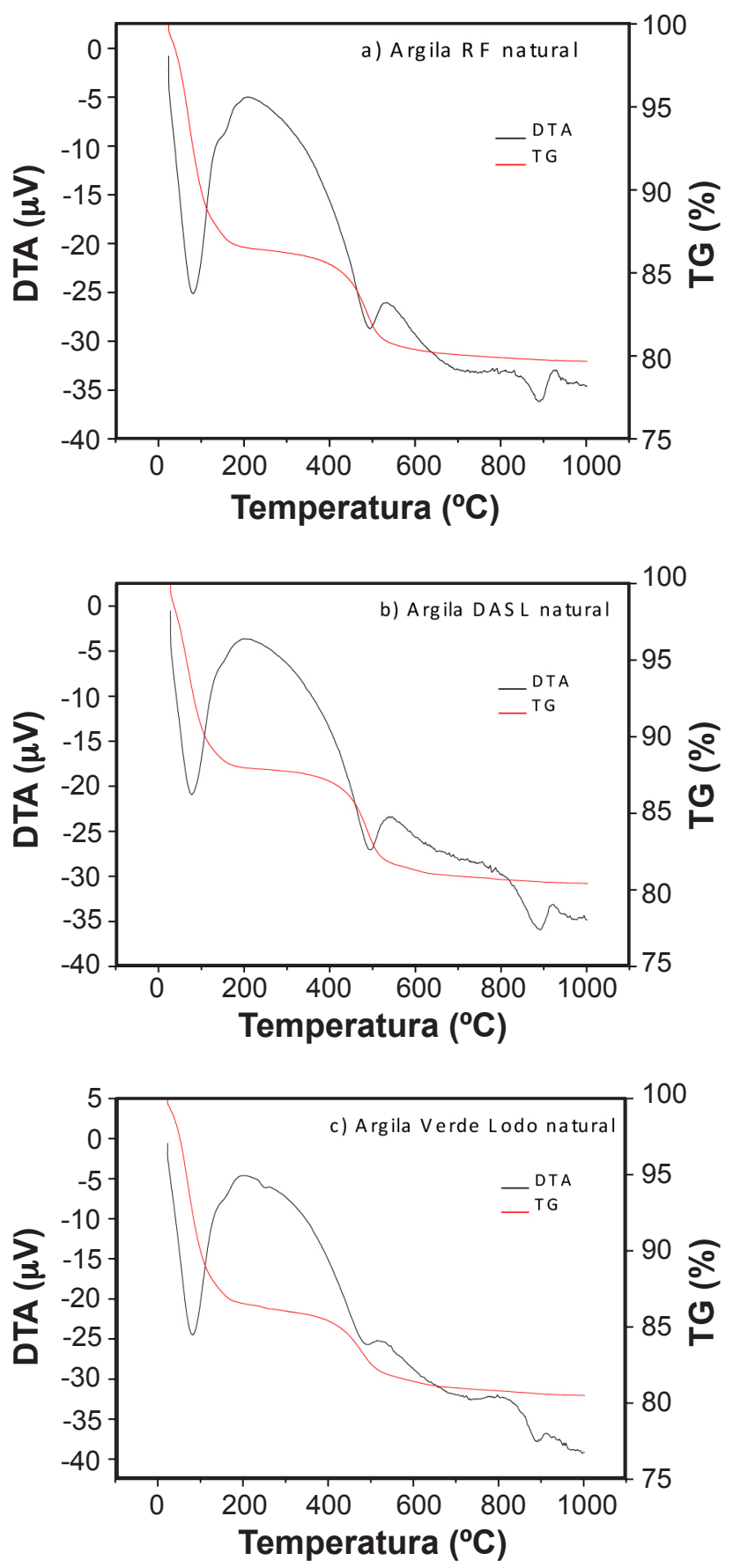

Figura 2: Comportamento térmico das argilas naturais: (a) RF, (b) DASL e (c) Verde Lodo.

[Figure 2: Thermal behavior of natural clays: (a) RF, (b) DASL, and (c) Verde Lodo.]

amostra DASL (Fig. 2b) perdeu o correspondente a 19,63\% de massa. Na Fig. 2c referente à amostra Verde Lodo é possível observar pico endotérmico entre a temperatura ambiente e $188{ }^{\circ} \mathrm{C}$ correspondente à perda de água livre, entre 190 e $391{ }^{\circ} \mathrm{C}$ correspondente à decomposição de matéria orgânica, e entre 400 e $500{ }^{\circ} \mathrm{C}$ um pico endotérmico correspondente à perda de hidroxilas. Por volta de $530{ }^{\circ} \mathrm{C}$ um pico exotérmico correspondente à queima do carbono residual, pico endotérmico por volta $890^{\circ} \mathrm{C}$ que se refere à
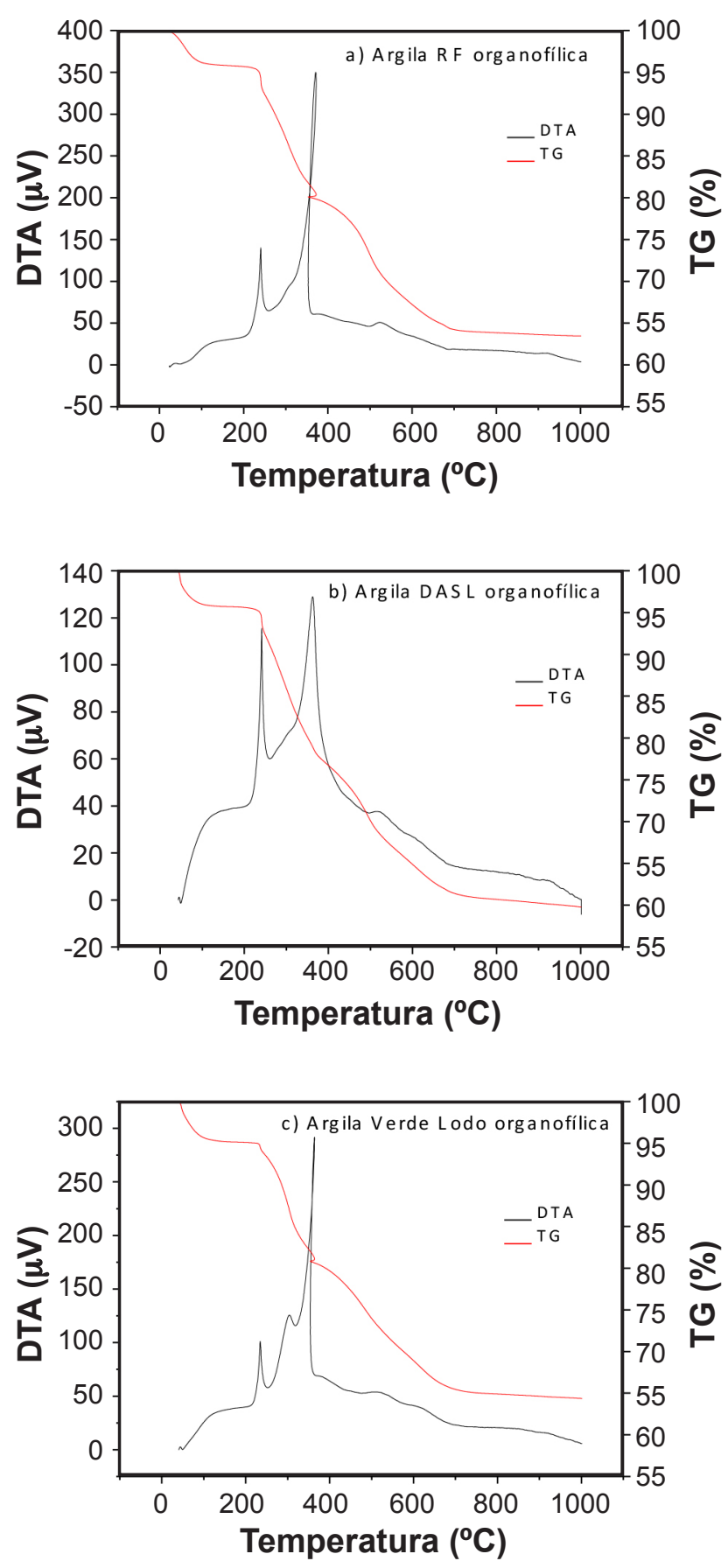

Figura 3: Comportamento térmico das argilas tratadas por organofilização: (a) RF, (b) DASL e (c) Verde Lodo.

[Figure 3: Thermal behavior of organophilic treated clays: (a) RF, (b) DASL, and (c) Verde Lodo.]

destruição do retículo cristalino e pico exotérmico ocorrido por volta de $912{ }^{\circ} \mathrm{C}$ que corresponde a formação de quartzo $\beta$, oriundo do excesso de sílica na nucleação da mulita. A curva de TG para a amostra Verde Lodo indicou perda de massa de $19,53 \%$. Resultados similares para comportamento térmico de tais amostras em estado natural encontram-se atualmente catalogados em literatura científica [18, 19]. Em análise da Fig. 3, observa-se que, de maneira comum para as três amostras em estudo, há dois intensos picos exotérmicos 
em uma faixa de temperatura em torno de 230 e $400{ }^{\circ} \mathrm{C}$, referente à decomposição do tensor orgânico. Em torno de $520{ }^{\circ} \mathrm{C}$ é possível observar ainda, de forma comum às três amostras organofílicas, que há mais um evento exotérmico provavelmente proveniente da queima de grafite residual. As curvas de TG indicaram que as perdas de massa foram de $36,54 \%$ na amostra RF organofílica (Fig. 3a), 40,20\% na amostra DASL organofílica (Fig. 3b) e 35,63\% na amostra Verde Lodo organofílica (Fig. 3c). Resultados similares para argilas bentoníticas sintetizadas a partir de sais quaternários de amônio encontram-se reportados na literatura [20].

Os resultados obtidos a partir do ensaio de teor de umidade das amostras bentonitas organofílicas e in natura, encontra-se na Tabela III. A ampla diferença de valores entre as amostras naturais e organofílicas pode estar relacionada ao fato de que as argilas após sintetizadas organofilicamente tornem-se hidrofóbicas. O valor estimado para uso farmacêutico e cosmético de argilas bentoníticas está compreendido em uma faixa máxima de até $15 \%$ em perda por secagem a $110 \pm 1^{\circ} \mathrm{C}$ [21], de modo que em análise isolada a este parâmetro é possível afirmar que as argilas do tipo organofílicas estão mais inclinadas ao preparo cosmético. A Tabela III também evidencia os resultados dos ensaios de adsorção de óleo para as amostras das argilas bentoníticas naturais e organofílicas. Os valores observados revelaram que a adsorção para argilas organofilizadas apresentaram incremento significativo, em termos percentuais, superiores a $100 \%$ para a amostra RF e para amostra DASL e pouco menor que o mesmo valor (em percentual) para a amostra verde lodo em relação às suas respectivas amostras em estado natural. A superioridade de valor adsortivo das argilas organofílicas é similar aos valores observados para argilas organofílicas, em modo comparativo a estas sob formanatural, reportado na literatura [22]. Na Tabela III estão relacionadas as densidades aerada e compactada para as amostras in natura e organofílicas. Os resultados apresentados para densidade aerada referente às argilas naturais são valores bem próximos aos resultados obtidos através deste ensaio para argilas organofílicas; o mesmo acontece para os ensaios de densidade compactada, demonstrando desta maneira que o processo de organofilização não ocasionou grandes interferências na densidade. A morfologia das partículas, distribuição granulométrica e a umidade do pó formam um conjunto de informações as quais são capazes de alterar os valores de densidade de um determinado material sob forma de pó [23].

Os resultados do CTC realizado nas argilas bentoníticas naturais estão impressos na Tabela IV. É possível observar que as três argilas possuem capacidade de troca semelhante; embora a amostra RF esteja pouco abaixo do esperado para argilas esmectitas, os resultados são considerados satisfatórios uma vez que a faixa compreendida para tais argilas está fixada entre 80 e 150 meq [1]. A elevada CTC auxilia na retenção de moléculas em sua estrutura [24], o que certamente é fator que favorece a obtenção de formulações cosméticas que confiram maior retenção de oleosidade natural da pele, o que reflete diretamente no tempo de duração do efeito de camuflagem, proporcionado pela maquiagem, sobre a pele. Um resumo da distribuição do tamanho de partículas das amostras bentoníticas naturais é apresentado na Tabela IV. As amostras apresentaram distribuição de tamanho de partículas semelhantes; entretanto, a argila DASL apresentou menor diâmetro médio e maior proporção de partículas acumuladas abaixo de $2 \mu \mathrm{m}$, evidenciando menor distribuição de partículas. É importante salientar que estudos científicos reportam que as argilas com dimensões em torno de $10 \mu \mathrm{m}$ e diâmetro médio de $26,33 \mu \mathrm{m}$ demonstraram por meio de ensaios in vivo eficiente atividade cicatrizante com recuperação profunda da derme lesionada por queimadura [25]. A indicação para uso cosmético em geral é de uma granulometria média de 44 a $37 \mu \mathrm{m}$ para aplicações cosméticas de pós prensados [21]. De todo modo afirma-se, de modo seguro, que quanto menor for as partículas, maior é a sua área superficial. Minerais com elevada área específica em conjunto com a característica de sorção de líquido, que em geral é peculiar às bentonitas, funcionam como protetores dermatológicos em pós, protegendo a pele contra exsudações, excreções líquidas do próprio corpo e agentes externos. Seu mecanismo funcional acontece por meio de sua alta aderência à pele formando uma película que oferece proteção contra agentes químicos e físicos externos [26, 27].

Tabela III - Teor de umidade, adsorção de óleo e densidades aerada e compactada das argilas bentoníticas naturais e organofílicas.

[Table III - Moisture content, adsorption of oil, and compressed and aerated densities of samples of natural and organophilic bentonite clays.]

\begin{tabular}{ccccc}
\hline Amostra & $\begin{array}{c}\text { Teor de umidade } \\
(\%)\end{array}$ & $\begin{array}{c}\text { Adsorção } \\
(\%)\end{array}$ & $\begin{array}{c}\text { Densidade aerada } \\
\left(\mathrm{g} / \mathrm{cm}^{3}\right)\end{array}$ & $\begin{array}{c}\text { Densidade } \\
\text { compactada }\left(\mathrm{g} / \mathrm{cm}^{3}\right)\end{array}$ \\
\hline RF natural & 13,42 & 1,359 & 0,60 & 1,05 \\
DASL natural & 12,01 & 1,411 & 0,66 & 1,11 \\
Verde Lodo natural & 13,45 & 1,725 & 0,60 & 1,05 \\
RF organofílica & 1,48 & 3,029 & 0,66 & 1,11 \\
DASL organofílica & 1,09 & 2,562 & 0,59 & 1,00 \\
Verde Lodo organofílica & 1,57 & 2,366 & 0,66 & 1,11 \\
\hline
\end{tabular}


Tabela IV - Capacidade de troca catiônica (CTC) e resumo da distribuição de tamanho de partículas das argilas bentoníticas naturais.

[Table IV - Cation exchange capacity (CTC) and summary of particle size distribution of natural bentonite clays.]

\begin{tabular}{cccccc}
\hline Amostra & CTC $(\mathrm{meq} / 100 \mathrm{~g})$ & $\mathrm{D}_{10}(\mu \mathrm{m})$ & $\mathrm{D}_{50}(\mu \mathrm{m})$ & $\mathrm{D}_{90}(\mu \mathrm{m})$ & Diâmetro médio $(\mu \mathrm{m})$ \\
\hline $\mathrm{RF}$ & 78,94 & 2,48 & 5,76 & 13,52 & 7,06 \\
DASL & 86,95 & 2,16 & 5,05 & 11,77 & 6,12 \\
Verde Lodo & 83,10 & 2,61 & 5,85 & 13,68 & 7,14 \\
\hline
\end{tabular}

\section{Formulação cosmética desenvolvida a partir de bentonitas}

Controle de qualidade: as amostras das formulações cosméticas foram avaliadas por meio de suas características organolépticas. Os parâmetros avaliados através desta análise envolvem alterações físicas e físico-químicas, tais como; aspecto, cor, odor e sabor. Os resultados, de maneira particular para cada formulação a partir de argilas naturais e organofílicas, podem ser avaliados na Tabela V ("antes do teste de estabilidade"). As formulações submetidas a estes ensaios demonstraram semelhanças no que se refere ao aspecto, cor, odor e sabor, durante todo o período de estudo e independente das possíveis alterações climáticas e condições de armazenamento, em modo comparativo às formulações tomadas como padrão e acondicionadas à temperatura ambiente. Estes resultados são correlatos aos encontrados em literatura [28]. Para as propriedades de fluxo inerentes do estudo da presente formulação, foi necessário, inicialmente, determinar as densidades bulk e compactada, e da razão de ambas foram obtidos os resultados do índice de Hausner que se encontram na Tabela VI conjuntamente com os resultados de ângulo de repouso ("antes do teste de estabilidade"). Todas as formulações testadas apresentaram valores de índice de Hausner maior que 1,4, o que as caracterizam como material coesivo de escoamento difícil [29]. O índice de Hausner caracteriza o atrito numa situação de movimento das partículas e quanto menor for o valor destas partículas maior é o atrito gerado por estas. O ângulo de repouso apresentou valores muito superiores a $55^{\circ}$ indicando de tal maneira um escoamento também muito difícil [30]. Fatores como umidade e tamanho de partículas envolvidos na

Tabela V - Resultados dos ensaios organolépticos para as formulações de pó mineral antes e após teste de estabilidade acelerada.

[Table V-Results of organoleptic assays for the formulations before and after accelerated stability test.]

\begin{tabular}{cllllll}
\hline \multirow{2}{*}{ Formulação } & \multicolumn{2}{c}{ Antes do teste de estabilidade } & \multicolumn{3}{c}{ Após teste de estabilidade acelerada } \\
& Cor & Odor & Aspecto & Cor & Odor & Aspecto \\
\hline RFN & Normal & Normal & Normal & Normal & Normal & Normal \\
DASLN & Normal & Normal & Normal & Normal & Normal & Normal \\
VLN & Normal & Normal & Normal & Normal & Normal & Normal \\
RFO & Normal & Normal & Normal & Normal & Normal & Normal \\
DASLO & Normal & Normal & Normal & Normal & Normal & Normal \\
VLO & Normal & Normal & Normal & Normal & Normal & Normal \\
\hline
\end{tabular}

Tabela VI - Propriedades de fluxo para as formulações de pó mineral antes e após teste de estabilidade acelerada. [Table VI - Flow properties for mineral powder formulations before and after accelerated stability test.]

\begin{tabular}{ccccc}
\hline \multirow{2}{*}{ Formulação } & \multicolumn{2}{c}{ Antes do teste de estabilidade } & \multicolumn{2}{c}{ Após teste de estabilidade acelerada } \\
& Índice de Hausner & Ângulo de repouso & Índice de Hausner & Ângulo de repouso \\
\hline RFN & 1,75 & $105^{\circ}$ & 1,74 & $101^{\circ}$ \\
DASLN & 1,68 & $100^{\circ}$ & 1,68 & $102^{\circ}$ \\
VLN & 1,75 & $100^{\circ}$ & 1,70 & $105^{\circ}$ \\
RFO & 1,68 & $158^{\circ}$ & 1,65 & $150^{\circ}$ \\
DASLO & 1,69 & $128^{\circ}$ & 1,72 & $123^{\circ}$ \\
VLO & 1,68 & $204^{\circ}$ & 1,70 & $205^{\circ}$ \\
\hline
\end{tabular}


formulação podem ter influenciado estes resultados.

A estabilidade acelerada reuniu um conjunto de características físicas e organolépticas, sendo que a alteração desta última poderia ser um indicativo de possíveis alterações químicas no sistema, capazes de assegurar a segurança do produto, bem como seu comportamento, frente às extremas condições de temperatura e umidade. A Tabela $\mathrm{V}$ evidencia as características organolépticas após estas serem submetidas aos ciclos de congelamento e descongelamento. É possível afirmar que as características organolépticas para todas as formulações não apresentaram alterações macroscopicamente observadas com relação à sua aparência, cor, odor e sabor quando foram comparadas aos resultados obtidos antes do ensaio de estabilidade. Com comportamento similar apresentam-se as propriedades de fluxo das formulações; a Tabela VI evidencia o comportamento físico, por meio destas propriedades, após o ciclo de congelamento e descongelamento ao qual foram submetidas as formulações na intenção de se verificar a estabilidade das mesmas. As formulações mantiveram propriedades de fluxo semelhantes àquelas apresentadas pelas formulações correspondentes antes de serem expostas ao ciclo de congelamento e subsequente descongelamento, assegurando a estabilidade das formulações.

Controle microbiológico: os resultados da contagem de microrganismos viáveis apontaram para a ausência de microrganismos contaminantes. Na Fig. 4 é possível visualizar a imagem das placas onde foram envolvidas as amostras em meio de cultura viável a crescimento bacteriano. A imagem evidencia a ausência de bactérias nas placas demonstrando que não houve, para nenhuma das formulações testadas, nenhum risco de contaminação bacteriana que possa vir a comprometer o sistema, o que torna as formulações seguras do ponto de vista biológico.

Segurança toxicológica: a exposição da membrana corioalantóide aos produtos das respectivas diluições foi acompanhada antes e após os 5 min de exposição; os registros fotográficos da Fig. 5 expõe o comportamento para algumas das soluções diluídas testadas após decorrido os 5 min. Em análise a tais imagens é possível constatar que nenhum evento indicativo de efeitos nocivos foi constatado. Para nenhuma das formulações estudadas, sejam estas desenvolvidas a partir de bentonitas em seu estado natural ou organofílico, foi detectada qualquer alteração ou, mais especificamente, indicativos de vasoconstrição, coagulação ou hemorragia. Os resultados de não citotoxicidade para as formulações de maquiagem mineral à base de argilas naturais já eram esperados e podem ser corroborados por recentes estudos desenvolvidos e reportados em literatura [31]. Todavia, o uso de surfactantes nas argilas organofílicas, sob a perspectiva da citotoxicidade, delineava-se como uma incógnita e, portanto, um ponto passível de investigação, uma vez que os sais quaternários de amônio podem apresentar reações alergênicas. Embora os compostos quaternários de amônio com sua aplicação sobre a pele seja considerada relativamente atóxica [32], e seu uso na modificação de argilas para liberação controlada

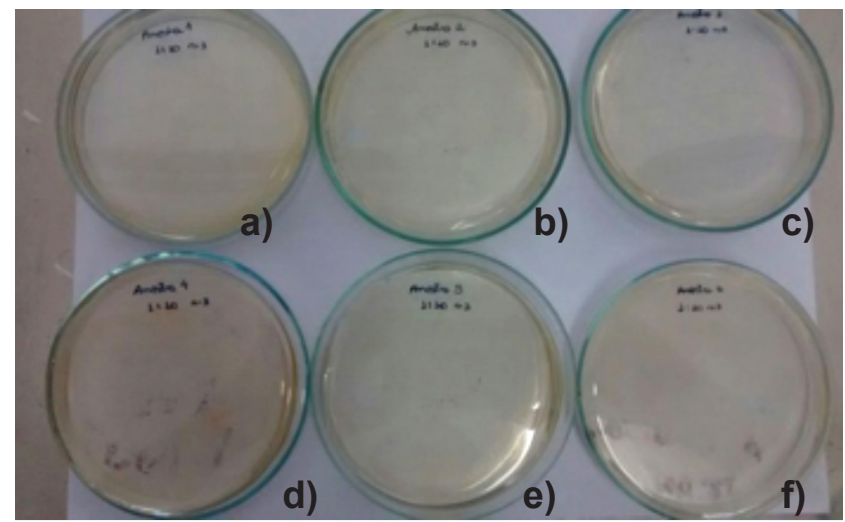

Figura 4: Análise microbiológica por plaqueamento para as formulações com argila: (a) RF natural; (b) DASL natural; (c) Verde Lodo natural; (d) RF organofílica; (e) DASL organofílica; e (f) Verde Lodo organofílica.

[Figure 4: Microbiological analysis by plating for the formulations with clay: (a) natural RF; (b) natural DASL; (c) natural Verde Lodo; (d) organophilic RF; (e) organophilic DASL; and $(f)$ organophilic Verde Lodo.]

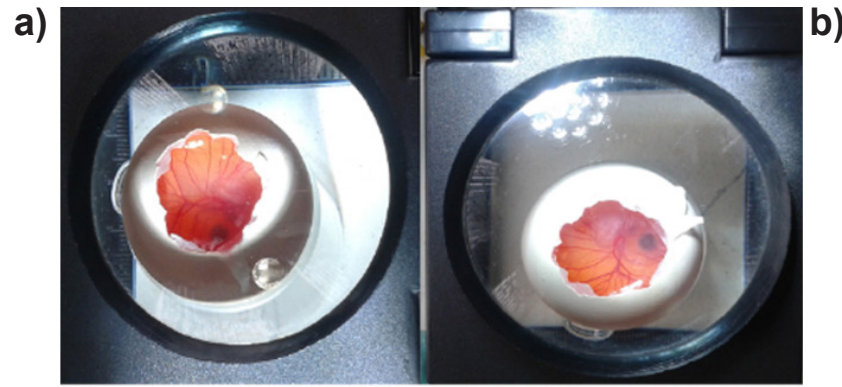

c)

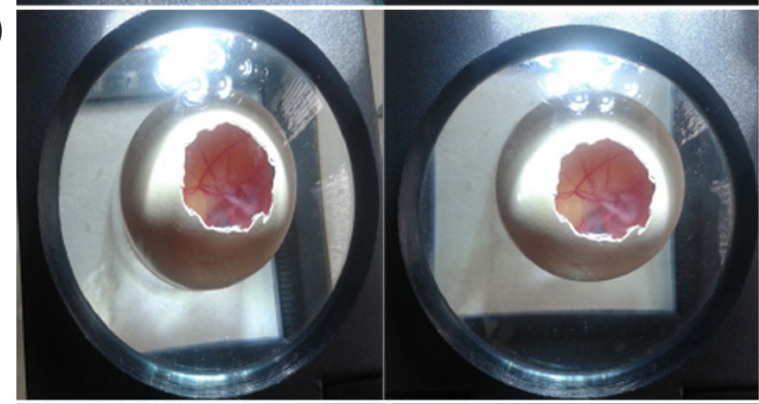

e)

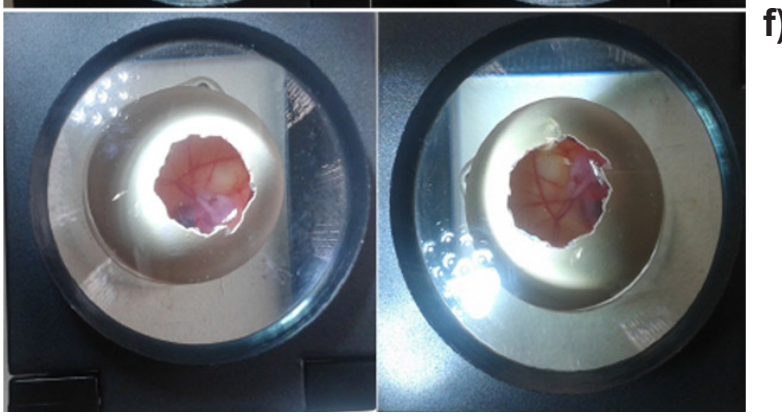

f)

Figura 5: Ensaio toxicológico HET-CAM para as formulações com argila: (a) RF natural; (b) DASL natural; (c) Verde Lodo natural; (d) RF organofílica; (e) DASL organofílica; e (f) Verde Lodo organofílica.

[Figure 5: HET-CAM toxicology test for formulations with clay: (a) natural RF; (b) natural DASL; (c) natural Verde Lodo; (d) organophilic RF; (e) organophilic DASL; and $(f)$ organophilic Verde Lodo.] 
de fármacos não apresente citotoxicidade sob determinadas concentrações [33], foi necessário cautela para verificação da influência ocorrida com relação à concentração desta substância e seus possíveis efeitos tóxicos sobre a pele do rosto e em possível contato com a região ocular, de modo que o uso de diferentes concentrações nos testes HET-CAM realizados permitem certo conforto com relação a afirmação de não citotoxicidade do composto de maquiagem mineral formulado a partir de argilas modificadas por meio de sais quaternários de amônio. Diante destes resultados, todo este processo foi protegido através do deposito de uma patente [34].

\section{CONCLUSÕES}

A partir do conjunto de ensaios que caracterizaram físico-quimicamente as argilas naturais e organofílicas foi possível avaliar que estas apresentam potencial tecnológico para aplicações em formulações cosméticas, o que permitiu, com uso das amostras de argilas naturais e organofílicas, como substância principal e em quantidade significativamente superior aos demais componentes da fórmula, obter formulações cosméticas de pó mineral para uso tópico. A partir dos ensaios de estabilidade acelerada realizados criteriosamente para cada uma das formulações desenvolvidas, e decorrente das caracterizações físicas e organolépticas realizadas após os ciclos de congelamento e aquecimento, foi possível admitir que as formulações são estáveis. O controle microbiológico das formulações permitiu a todas as formulações por meio da contagem de microrganismos viáveis verificar a ausência de possíveis microrganismos que comprometessem o sistema, uma vez que seus resultados foram negativos a crescimento de bactérias. A citotoxicidade pelo método da membrana corioalantóide do ovo embrionário da galinha permitiu observar que as formulações desenvolvidas para as amostras naturais e organofílicas não apresentaram toxicidade. A ausência de coagulação, hemorragia, vasoconstrição ou qualquer efeito indicativo de nocividade sobre a membrana do ovo após aplicação da formulação diluída em água destilada assegurou a veracidade dos resultados. De modo geral, pode-se concluir que, através dos estudos desenvolvidos a fim de verificar o potencial tecnológico das argilas bentoníticas naturais e organofílicas, estas apresentam potencial para aplicações cosméticas em maquiagem mineral, e que as formulações desenvolvidas a partir destas apresentam estabilidade e segurança biológica e toxicológica.

\section{REFERÊNCIAS}

[1] P. Souza Santos, Tecnologia de argilas aplicada às argilas brasileiras, Ed. Un. S. Paulo (1975).

[2] H.H. Murray, Appl. Clay Sci. 17, 5 (2000) 207.

[3] C. Viseras, C. Aguzzi, P. Cerezo, A. Lopez-Galindo, Appl. Clay Sci. 36, 1 (2007) 37.

[4] W. Chrzanowski, S.Y. Kim, E.A.A. Neel, Aust. J. Chem. 66, 11 (2013) 1315.
[5] M.G. Silva-Valenzuela, C.M. Matos, L.A. Shah, F.M.S. Carvalho, I.J. Sayeg, F.R. Valenzuela-Diaz, Int. J. Modern Eng. Res. 1, 3 (2013) 163.

[6] V. Zague, D.D. Almeida Silva, A.R. Baby, T.M. Kaneko, M.V. Robles Velosco, J. Cosmet. Sci. 58, 1 (2007) 45.

[7] M.T. Droy-Lefaix, F. Tateo, in Handbook of clay science, Vol. 1, Eds.: F. Bergaya, B.K.G. Theng, G. Lagaly, Elsevier, Amsterdam (2006) 743.

[8] S.R.A. Oliveira, M.L. Alves, C.S. Morais, C.D.Ó. Pessoa, Rev. GEINTEC 2, 2 (2012) 174.

[9] K. Arthur, L.C. do Nascimento, D.A. da Silva Figueiredo, L.B. de Souza, F.M. Alfieri, Acta Fisiátr. 19, 1 (2016) 11.

[10] H. Komine, N. Ogata, Can. Geotechn. J. 31, 4 (1994) 478.

[11] A.B. Luz, C.H. Oliveira, in Rochas \& minerais industriais, Eds.: A.B. Luz, F.A.F. Lins, Cetem/MCT, Rio de Janeiro (2005) 217.

[12] R.R. Menezes, P.M. Souto, L.N.L. Santana, G.A. Neves, R.H.G.A. Kiminami, H.C. Ferreira, Cerâmica 55 (2009) 163.

[13] I.D.S. Pereira, V.N.F. Lisboa, I.A. Silva, J.M.R. Figueirêdo, G.A. Neves, R.R. Menezes, Mater. Sci. Forum 820 (2015) 65.

[14] H.S. Ferreira, L.F.A. Campos, R.R. Menezes, J.M. Cartaxo, L.N.L. Santana, G.A. Neves, H.C. Ferreira, Cerâmica 59 (2013) 277.

[15] Ag. Nac. Vig. Sanit., "Guia de controle de qualidade de produtos cosméticos", ANVISA, Brasília-DF, 2 2 Ed. (2008). [16] P. Juliano, G.V. Barbosa-Cánovas, Annu. Rev. Food Sci. Technol. 1 (2010) 211.

[17] H.S. Ferreira, R.R. Menezes, A.B. Martins, G.A. Neves, H.C. Ferreira, Cerâmica 54, 329 (2008) 77.

[18] J.M.R. Costa, I.A. Silva, H.S. Ferreira, R.R. Menezes, G.A. Neves, H.C. Ferreira, Cerâmica 58, 348 (2012) 419.

[19] M.F. Marques, M.L. Moreira, Rev. Bras. Farm. 90, 2 (2009) 137.

[20] L.B. Paiva, A.R. Morales, F.V. Díaz, Cerâmica 54, 330 (2008) 213.

[21] A. López-Galindo, C. Viseras, P. Cerezo, Appl. Clay Sci. 36, 1 (2007) 51.

[22] M.M. Silva, A.C.L. Patrício, W.S . Lima, H.M. Laborde, M.G.F. Rodrigues, Scientia Plena 7 (2011) 9.

[23] I.L.T. Dias, Rev. Eletr. Farm. 9, 4 (2012) 19.

[24] C. Aguzzi, P. Cerezo, C. Viseras, C. Caramella, Appl. Clay Sci. 36, 1 (2007) 22.

[25] G.M. Dário, "Avaliação da atividade cicatrizante de formulação contendo argila medicinal sobre feridas cutâneas em ratos", Diss. Mestr., Un. Extremo Sul Catarinense (2008). [26] M.I. Carretero, C.S.F. Gomes, F. Tateo, in Handbook of clay science, Vol. 1, Eds.: F. Bergaya, B.K.G. Theng, G. Lagaly, Elsevier, Amsterdam (2006) 717.

[27] M.I. Carretero, M. Pozo, Appl. Clay Sci. 47, 3 (2010) 171.

[28] M.L.G. Silva, "Obtenção e caracterização de argila piauiense paligorsquita (atapulgita) organofilizada para uso em formulações cosméticas", Diss. Mestr., Un. Fed. Piauí (2011) 67. 
[29] E.C. Abdullah, D. Geldart, Powder Technol. 102, 2 (1999) 151.

[30] C.R. Woodcock, J.S. Mason, Bulk solids handling, $2^{\text {nd }}$ Ed., Springer, Netherlands (2012).

[31] J. Nones, H. Riella, N. Kuhnen, A. Trentin, Blucher Chem. Eng. Proc. 1, 2 (2015) 1920.

[32] T.C.C. Parlato, L.M. Vital, Rev. Bras. Enferm. 25, 1-2
(1972) 52.

[33] D.M. Flórido, "Produção de microesferas de nanocompósitos de quitosano e argila para libertação controlada de fármacos", Tese Dr., Un. Nova Lisboa (2013). [34] Patente BR1020170050432, "Formulação cosmética de pó facial do tipo mineral a base de argila bentonítica em estado natural e organofílico", INPI (2017). (Rec. 23/05/2017, Rev. 27/09/2017, Ac. 21/11/2017) 